\title{
HPLC Fingerprint of Bioactive Compounds and Antioxidant Activities of Viscum album from Different Host Trees
}

\author{
Simona Ioana VICAŞ ${ }^{\prime}$, Dumitrița RUGINǍ², Loredana LEOPOLD², \\ Adela PINTEA ${ }^{2}$, Carmen SOCACIU ${ }^{2}$ \\ ${ }^{1}$ University of Oradea, Faculty of Environmental Protection, 26 Gen. Magheru, 410048 Oradea, Romania; svicas@uoradea.ro \\ ${ }^{2}$ University of Agricultural Sciences and Veterinary Medicine, 3-5 Mănăş̆tur, 400372 Cluj-Napoca, Romania; csocaciu@usamv.ro
}

\begin{abstract}
Viscum album L. is a medicinal plants used for many years as a remedy in the traditional medicine and in complementary cancer therapies. We investigated the influence of some host trees: Acer campestre (VAA), Fraxinus excelsior (VAF), Populus nigra (VAP), Malus domestica (VAM), and Robinia pseudoacacia (VAR), on the chemical composition and antioxidant activity of leaves and stems from $V$. album, as well the influence of the solvent (water and ethanol) used for extraction on biological activity. HPLC with photodiode array detector analysis of bioactive compounds from leaves and stems of mistletoes ( $V$. album) hosted by five differents trees was performed Antioxidant activities, determined by the 2,2-diphenyl-1-picrylhydrazyl (DPPH), Oxygen Radical Absorbance Capacity (ORAC), (Trolox-equivalent antioxidant capacity (TEAC) methods were compared with the quantification of total phenolics using the Folin -Ciocalteu reagent. $V$. album hosted by Fraxinus excelsior (VAF), recorded the highest level of total phenolic acids $(108.64 \mu \mathrm{g} / \mathrm{g} \mathrm{dry}$ matter) while the mistletoe hosted by Malus domestica (VAM) had the lowest level of total polyphenols (39.37 $\mu \mathrm{g} / \mathrm{g}$ dry matter). In general, higher antioxidant activity was detected in the alcoholic than in the aqueous extracts. The values obtained for total phenolics in both, aqueous and ethanol extracts, decreased in the order: VAR > VAF > VAP > VAA > VAM. The mistletoe stem extracts contained lower levels of phenolics, as compared to leaves, in both solvents. Our results suggest that mistletoe extracts possess significant antioxidant activities that may be due to their bioactive compounds content, suggesting that this plant may be an important source of natural products with chemopreventive and chemotherapeutic activities.
\end{abstract}

Keywords: Viscum album, HPLC-fingerprint, DPPH, ORAC, TEAC, total polyphenols

\section{Introduction}

In search of novel sources of antioxidants, medicinal plants, especially those used in traditionally folk medicine, have been extensively studied in the last years for their antioxidant activity (Li at al., 2008; Borneo et al., 2009; Antal, 2010; Djeridane et al., 2010; Kratchanova et al., 2010). European mistletoe (Viscum album L.) is an evergreen, semiparasitic plant, normally found growing on a variety of trees, especially pine, poplar, apple trees, locus trees etc. Although there are many varieties of mistletoe, including the American (Phorandendron serotinum or Phorandendron flavescens), the European (Viscum album L.), and the Korean (Viscum album L. coloratum), most research work has been done on European mistletoe. A number of biological effects, such as anticancer, apoptosis-inducing, antimicotic, antibacterial, antiviral, and immunomodulatory activities have been reported (Hajtó et al., 2005).

The flavonoids and phenolic acids present in the plants are natural antioxidants. The most investigated chemical property of the phenolic compounds is their antioxidant activity. Quercetin, a flavonol, has been demonstrated to display a very strong antioxidant activity, often accompanied by antiviral and antibacterial activity (Materska,
2008). Phenolic acids are a ubiquitous plant constituents that arises from the metabolism of phenylalanine and tyrosine. Due to their phenolic nucleus and an extended side hain conjugation, they readly forms a resonance stabilized phenoxy radical which accounts for their potent antioxidant potential (Graf, 1992).

The phytochemical profile of mistletoe depends on the host trees of this plant (Luczkiewicz et al., 2001). The main bioactive compounds found in mistletoe are lectins (glycoproteins with effects on cell-proliferation) and viscotoxin (a small protein molecule of $5 \mathrm{kDa}$ ) (Edlund et al., 2000; Romagnoli et al., 2000). Alkaloid concentration is usually low, and dependent on the host tree type (Peng et al., 2005). It is considered that, flavonols like quercetin, kampherol and their methyl derivatives, and flavonone, naringenin, are the antioxidant compounds in mistletoe (Haas et al., 2003). Among the phenolic acids presents in mistletoe, digallic and $o$-coumaric acid in the free or glycosilated forms (Luczkiewicz et al., 2001) are also considered to be compounds with antioxidant activity.

The antioxidant capacity of many plant extracts is related to the presence of phenolic compounds (Miliauskas et al., 2004; Aqil et al., 2006; Roman et al., 2009). 
ÖnayUçar et al. (2006) investigated the antioxidant activity of methanol $V$. album extracts, using DPPH, ferric thiocyanate, and thiobarbituric acid methods. The authors showed that the antioxidant activity of mistletoe extracts depends both on the harvesting time and on the host trees. Also, the antioxidant effects of Viscum coloratum were found to be associated to the flavonoid fraction (Leu et al., 2006; Shi et al., 2006; Yao et al., 2006).

Choudhary et al. (2010) isolated from the methanol extract of $V$. album six compounds which were found to posses anti-glycation activity, whereas 3-(4-acetoxy-3,5dimethoxy)-phenyl-2E-propenyl- $\beta$-D-glucopyranoside and 4,5-dimethoxy-7-hydroxy flavanone exhibited antioxidant activity.

Viscum album aqueous extracts are used in complementary and alternative medicine as immunomodulators in cancer therapy. Based on this fact, we decided to evaluate the antioxidant activity of aqueous and ethanol extracts from leaves and stems of mistletoe.

The objective of the current study was to investigate the influence of host trees on the phenolics composition, and to compare the antioxidant activities of $V$. album samples originating from five different host trees.

\section{Materials and methods}

\section{Plant material}

Leaves and stems of $V$. album were harvested in July 2009, from five different host trees located in the BorodGheghie region, North-West of Romania country. The plant materials were labeled according to the host trees, thus: Acer campestre (VAA), Malus domestica (VAM), Fraxinus excelsior (VAF), Populus nigra (VAP) and Robinia pseudoacacia (VAR) for easy identification. A voucher specimen of the plants was deposited in the herbarium of the Environmental Protection Faculty from University of Oradea.

\section{Extraction methods}

Extraction and isolation of bioactive compounds for HPLC analysis

The leaves and stems of $V$. album from different host trees were dried rapidly, in an oven at $90^{\circ} \mathrm{C}$, for 48 hours, in order to prevent enzymatic degradation (Markham, 1982). The dried plant material was stored in a sealed plastic bag for HPLC analysis. After weighing out a portion of the dried material (approximately $1 \mathrm{~g}$ ), extraction was carried out with ethanol $70 \%(1: 10, \mathrm{w} / \mathrm{v})$. The mixture was stirred for 24 hours in the dark, and then it was centrifuged for 5 minutes, at $3000 \mathrm{rpm}$. The ethanol fraction of the supernatant was removed using a rotatory evaporator. Further, the aqueous extract was subjected to acid hydrolysis $(1 \mathrm{~N}$ $\mathrm{HCl}$ ) for 2 hours, at $80^{\circ} \mathrm{C}$. The aglycones were extracted 3 times with ethyl acetate by continuous stirring and then centrifuged at $5000 \mathrm{rpm}$, for 5 minutes. The solvent was removed by flushing the samples with nitrogen. The residue resulting after evaporation was dissolved in ultrapure water $(300 \mu \mathrm{l})$, filtered throught $0.45 \mu \mathrm{m}$ filters (MillexLG, Millipore), and subjected to HPLC analysis.

\section{Preparation of aqueous and ethanol mistletoe extracts for} antioxidant activity assay

Fresh leaves and stems $(2 \mathrm{~g})$ were homogenized with $10 \mathrm{ml}$ distilled water, or with $10 \mathrm{ml} 98 \%$ ethanol using a Ultra Turax homogenizator, for 1 minute. This mixture was centrifuged $\left(10000 \mathrm{rpm}\right.$, at $4^{\circ} \mathrm{C}$, for 10 minutes $)$ and the supernatants were filtered through a filter paper. The filtrate was used for the antioxidant activity measurements and total phenolics content.

\section{HPLC separation of phenolic compound}

A Shimadzu HPLC system equipped with a LC20AT binary pump, a degaser, a SPD-M20A diode array detector (Shimadzu Corp., Kyoto, Japan) and a SUPELCOSIL ${ }^{\mathrm{TM}}$ LC-18 column (Sigma-Aldrich Co), $5 \mu \mathrm{m}, 25 \mathrm{~cm} \times 4.6 \mathrm{~mm}$ was used. Gradient elution was performed with mobile phase A, composed of methanol: acetic acid: double distilled water $(10: 2: 88 \mathrm{v} / \mathrm{v} / \mathrm{v})$ and mobile phase $\mathrm{B}$, comprising methanol: acetic acid: double distilled water (90:3:7 $\mathrm{v} / \mathrm{v} / \mathrm{v}$ ), at a flow rate of $1.0 \mathrm{ml} / \mathrm{min}$. All solvents were HPLC grade solvents, filtered through a $0.45-\mu \mathrm{M}$ membrane (Millipore, U.S.A.) and degassed in an ultrasonic bath before use. The chromatograms were monitored at 280 and $360 \mathrm{~nm}$. The following pure standards were used to quantify the bioactive compounds in the leaves and stems of mistletoe: betulinic acid, gallic acid, protocatechuic acid, gentisic acid, chlorogenic acid, $\mathrm{p}-\mathrm{OH}$ benzoic acid, caffeic acid, syringic acid, salicilyc acid, p-coumaric acid, ferulic acid, sinapic acid, trans-cinamic acid, naringenin, quercetin, kaempherol and rosmarinic acid. The quantification was made by comparison to calibration curves with pure standards, in the range 0.48 to $500.0 \mu \mathrm{g} /$ $\mathrm{ml}$. The regression coeficients of calibration curves ranged between 0.9812 and 0.9999 . Integration and data analysis were made using Origin 7.0 software.

\section{Determination of antioxidant activities}

\section{2,2-diphenyl-1-picrylhydrazyl (DPPH) method}

The DPPH radical-scavenging activity was determined using the method proposed by Brand-Williams et al. (1995). The reaction was performed in 12 well-plate. A volume of $200 \mu \mathrm{l}$ sample and $1.4 \mathrm{ml}$ DPPH solution (80 $\mu \mathrm{M})$ were added to each microplate well. The decrease in the absorbance of the resulting solution was monitored at $515 \mathrm{~nm}$ for $30 \mathrm{~min}$. The percentage of scavenging effect of different extracts against DPPH radicals, was calculated using the following equation:

DPPH scavenging effect $(\%)=\left[\left(\mathrm{A}_{0}-\mathrm{A} s\right) \times 100\right] / \mathrm{A}_{0}$

Where, $A_{0}$ is absorbance of the blank, and $A_{S}$ is absorbance of the samples at $515 \mathrm{~nm}$. 
50

Oxygen Radical Absorbance Capacity (ORAC) method

The ORAC method measures antioxidant inhibition of peroxyl radical-induced oxidations, and thus reflects classical radical chain breaking antioxidant activity by hydrogen atom transfer. The ORAC assay was performed essentially as described by Huang et al. (2002). A volume of $150 \mu \mathrm{l}$ of working solution of sodium fluorescein ( 4 x 10-3 $\mathrm{mM}$ ) was added to $25 \mu \mathrm{l}$ samples, in a 12 well-microplate. The plate was allowed to equilibrate by incubating it for a minimum of 30 minutes in the Synergy ${ }^{\text {rix }}$ HT Multi-Detection Microplate Reader (BioTek Instruments, Winoos$\mathrm{ki}, \mathrm{VT})$ at $37^{\circ} \mathrm{C}$. Reaction was initiated by the addition of $25 \mu \mathrm{l}$ of 2,2'-azobis (2-amidino-propane) dihydrochloride $(\mathrm{AAPH})$ solution $(153 \mathrm{mM})$ and the fluorescence was then monitored kinetically with data taken every minute, at $485 \mathrm{~nm}, 20 \mathrm{~nm}$ bandpass excitation filter, and a $528 \mathrm{~nm}$, $20 \mathrm{~nm}$ bandpass emission filter. ORAC values were calculated as described by Cao and Prior (1998). The area under the curve (AUC) and the Net AUC of the standards and samples were determined using equations 1 and 2 respectively.

AUC $=0.5+(\mathrm{R} 2 / \mathrm{R} 1)+(\mathrm{R} 3 / \mathrm{R} 1)+(\mathrm{R} 4 / \mathrm{R} 1)+\ldots+0.5(\mathrm{Rn} / \mathrm{R} 1) \quad(\mathrm{Eq} .1)$

Where R1-fluorescence value at the initiation of reaction and $\mathrm{Rn}$-fluorescence value after $30 \mathrm{~min}$.

Net $\mathrm{AUC}=\mathrm{AUC}_{\text {sample }}-\mathrm{AUC}_{\text {blank }}$

The standard curve was obtained by plotting the Net AUC of different Trolox concentrations against their concentration $(6.25-100 \mu \mathrm{M})$. ORAC values of samples were then calculated automatically using Microsoft Excel to interpolate the sample's Net AUC values against the Trolox standard curve.

\section{Trolox Equivalents Antioxidant Capacity (TEAC) assay}

The TEAC is a spectrophotometric method, widely used for the assessment of antioxidant activity of various substances. This method measures the ability of compounds to scavenge the 2,2'-azino-bis(3-ethylbenzthiazoline-6-sulphonic acid) (ABTS) radical cation in relation to Trolox. ABTS was dissolved in distilled water to a $7 \mathrm{mM}$ concentration. $\mathrm{ABTS}^{+}$was produced by reacting $\mathrm{ABTS}$ stock solution with $2.45 \mathrm{mM}$ potassium persulfate and allowing the mixture to stand, in the dark, at room temperature for 12-16 h before use. ABTS stock solution was diluted with ethanol in order to obtain an absorbance of $0.70 \pm 0.02$ at $734 \mathrm{~nm}$. After addition of $17 \mu \mathrm{l}$ of extract to $170 \mu \mathrm{l}$ of diluted $\mathrm{ABTS}^{+}$, the interaction between the antioxidants and the $\mathrm{ABTS}^{+}$was monitored spectrophotometrically at $734 \mathrm{~nm}$ (Arnao et al. 2001). The results were expressed in $\mathrm{mM}$ Trolox equivalent/g fresh matter.

\section{Total phenolics determinated by the Folin-Ciocalten method}

Total phenolic content was determined by the FolinCiocalteu method (Singleton et al., 1999). Mistletoe extract $(23 \mu \mathrm{l})$ was mixed with $1817 \mu \mathrm{l}$ distillated water, 115 $\mu$ Folin-Ciocalteu reagent (dilution 1:10, v/v) and 345 $\mu \mathrm{l}$ of $15 \% \mathrm{Na}_{2} \mathrm{CO}_{3}$ solution, and the mixture incubated at room temperature, in the dark, for 2 hours. The absorbance was measured at $765 \mathrm{~nm}$ using a spectrophotometer (BioTek Synergy). The calibration curve was linear for the range of concentrations between $0.1-0.5 \mathrm{mg} / \mathrm{ml}$ gallic acid. The results were expressed in $\mathrm{mg}$ gallic acid equivalents (GAE)/g fresh matter).

\section{Statistical analysis}

All data were expressed as mean \pm standard deviation (SD) of three replications for each mistletoe extract tested. The data obtained from the antioxidant activity tests were analyzed statistically by the one-way analysis of variance (ANOVA) and Tukey's Multiple Comparison Test to compare each extract to VAA extract. The probability level of less than 0.05 was accepted as significant. An overall antioxidant potency composite index was determined by assigning an index value of 100 to the best score for each test, and then calculated an index score for all other samples within the test as follows: antioxidant index score $=[($ sample score/best score $) \times 100]$ (Seeram et al., 2008). The average of all four tests for each mistletoe extract was then taken for the antioxidant potency composite index.

\section{Results and discussion}

\section{Evaluation of phenolics content by HPLC analysis}

Quantitative data regarding the phenolic compounds composition of mistletoe extracts are shown in Tab. 1. HPLC chromatograms of phenolic acids from leaves and stems of Viscum album hosted by different trees: Acer campestre (VAA), Fraxinus excelsior (VAF), Populus nigra (VAP), Malus domestica (VAM), and Robinia pseudoacacia (VAR) are presented in Fig. 1.

We identified and quantified 17 compounds from mistletoe samples (Tab. 1), including a pentacyclic triterpene (betulinic acid), 12 phenolic acids (gallic acid, protocatechuic acid, gentisic acid, chlorogenic acid, $\mathrm{p}-\mathrm{OH}$ benzoic acid, caffeic acid, syringic acid, salicilyc acid, p-coumaric acid, ferulic acid, sinapic acid, and trans-cinamic acid) and 4 polyphenols (naringenin, quercetin, kaempherol and rosmarinic acid). These compounds were identified according to their retention time and the spectral characteristics of their peaks compared with standards, as well as by spiking the sample with individual standards. Phenolic compounds are found usually in nature as esters and rarely as glycosides or in free form. Thus, hydrolysis was needed for their identification and quantitative determination. Flavonoids are also present in plants in the form of glycosides. Each flavonoid may occur in a plant in several glycosidic combinations. For this reason, hydrolysis was used to release the aglycones which were further investigated by HPLC.

Quantitative HPLC analysis of $V$. album showed a higher content of bioactive compounds in the leaves com- 

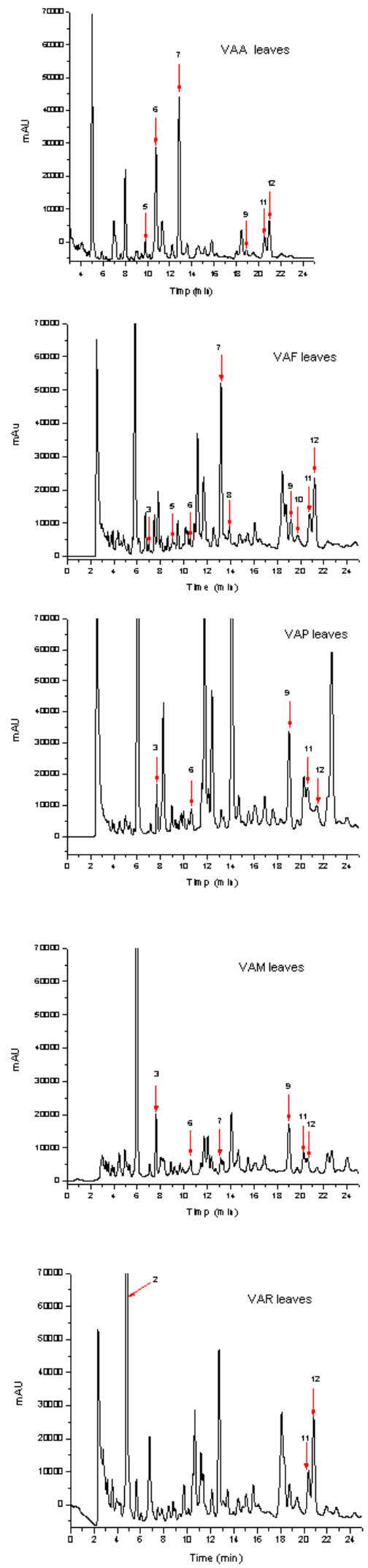
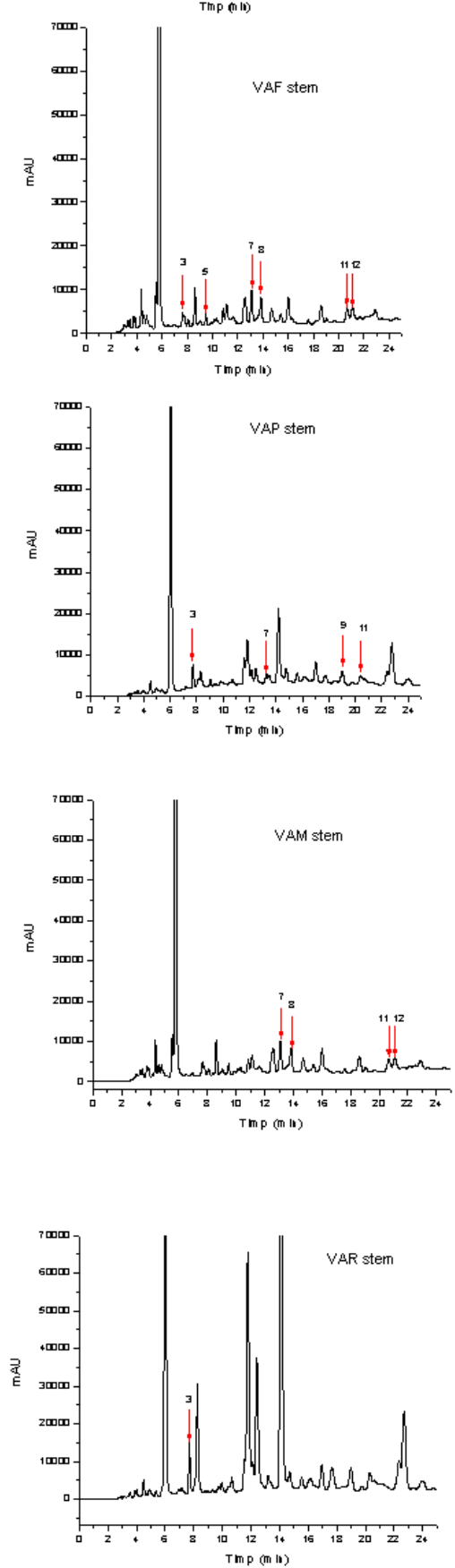

Fig. 1. HPLC chromatograms, used to fingerprint and evaluate quantitatively phenolic acids from leaves and stems of V.album harvested from different host trees: VAA - mistletoe from Acer campestre, VAF - mistletoe from Fraxinus excelsior, VAP mistletoe from Populus nigra, VAM - mistletoe from Malus domestica and VAR- mistletoe growing on Robinia pseudoacacia. The peak numbers are identified in Tab. 1 
52

pared with stems (Tab. 1). In the case of leaves from $V$. album hosted by Acer campestre (VAA), seven phenolic acids and three polyphenols were identified, while in the stem of mistletoe we found only one phenolic acid (transcinnamic acid). Caffeic acid was the dominant compound $(13.61 \mathrm{\mu g} / \mathrm{g}$ dry matter) in the leaves of mistletoe. Kampherol and rosmarinic acid were presented in both, leaves and stems, while quercetin was identified only in leaves.

The mistletoe hosted by Fraxinus excelsior (VAF) contains nine phenolic acids, and two flavonoids. Concentration of para-coumaric acid in theVAF sample was $1.82 \mu \mathrm{g} / \mathrm{g}$ dry matter, but we have not identified it in other mistletoe extracts. Caffeic acid was found to have the higest values both in leaves $(13.98 \mu \mathrm{g} / \mathrm{g}$ dry matter) and stems (15.86 $\mu \mathrm{g} / \mathrm{g}$ dry matter). Kaempherol was also present both in leaves $(7.30 \mu \mathrm{g} / \mathrm{g}$ dry matter) and stems $(3.66 \mu \mathrm{g} / \mathrm{g}$ dry matter), while quercetin was present only in leaves (6.05 $\mu \mathrm{g} / \mathrm{g}$ dry matter).

In case of $V$. album collected from Populus nigra (VAP), ferrulic acid was a dominant compound in the set of phenolic acids both in leaves $(11.52 \mu \mathrm{g} / \mathrm{g}$ dry matter) and in stems $(6.14 \mu \mathrm{g} / \mathrm{g}$ dry matter). Salycilic acid was also present in VAP leaves $(8.4 \mathrm{\mu g} / \mathrm{g}$ dry matter) and stems (2.3 $\mu \mathrm{g} / \mathrm{g}$ dry matter), while in the other mistletoe samples it was detected only in leaves.

The HPLC chromatogram of mistletoe hosted by Malus domestica (VAM) showed seven phenolic acids in leaves. Betulinic acid was present only in this mistletoe, both in leaves $(1.87 \mu \mathrm{g} / \mathrm{g}$ dry matter $)$ and stems $(2.05 \mu \mathrm{g} / \mathrm{g}$ dry matter). Also, like in mistletoe hosted by $P$. nigra, ferulic acid was the main compound in leaves and stems (7.81 $\mu \mathrm{g} / \mathrm{g}$ dry matter, and $6.88 \mu \mathrm{g} / \mathrm{g}$ dry matter, respectively) of VAM samples.

The main compound in $V$. album hosted by Robinia pseudoacacia (VAR) was gallic acid $(39.93 \mu \mathrm{g} / \mathrm{g}$ dry matter), which has not been found in the other samples studied.

it has been not detect gentisic acid in any sample, nor naringenin, while quercetin was identified only in stems.

Phenolic acids represent the major fraction of bioactive compounds in all $V$. album. A high variability of phenolic acid rations between leaves and stems was observed. While, VAA and VAR had high ratios (43.51:1 and 34.41:1, respectively) the lowest ratios were observed in the case of VAF and VAM (1.21:1 and 1.44:1, respectively).

In our study, the mistletoe hosted by Fraxinus excelsior (VAF) proved to be the richest in phenolic acids (108.64

Tab. 1. Quantitative HPLC analysis of bioactive aglicones of phenolics ( $\mu \mathrm{g} / \mathrm{g}$ dry matter ${ }^{*}$ ) from leaves and stems of $V$. album harvested from different hosts, on July 2009. For abbreviations, see materials and methods

\begin{tabular}{|c|c|c|c|c|c|c|c|c|c|c|c|}
\hline \multirow{2}{*}{$\begin{array}{l}\text { Com. } \\
\text { no. }\end{array}$} & \multirow[t]{2}{*}{ Bioactive compounds } & \multicolumn{2}{|c|}{$\begin{array}{c}\text { VAA } \\
\text { Acer campestre }\end{array}$} & \multicolumn{2}{|c|}{$\begin{array}{c}\text { VAF } \\
\text { Fraxinus excelsior }\end{array}$} & \multicolumn{2}{|c|}{$\begin{array}{c}\text { VAP } \\
\text { Populus nigra }\end{array}$} & \multicolumn{2}{|c|}{$\begin{array}{c}\text { VAM } \\
\text { Malus domestica }\end{array}$} & \multicolumn{2}{|c|}{$\begin{array}{c}\text { VAR } \\
\text { Robinia pseudocacia }\end{array}$} \\
\hline & & leaves & stems & leaves & stems & leaves & stems & leaves & stems & leaves & stems \\
\hline \multicolumn{12}{|c|}{ Pentacyclic triterpene } \\
\hline 1. & Betulinic acid & nd & nd & nd & $2.35 \pm 0.03$ & nd & nd & $1.87 \pm 0.20$ & $2.05 \pm 0.05$ & nd & nd \\
\hline \multicolumn{12}{|c|}{ Phenolic acids } \\
\hline 2. & Gallic acid & nd & nd & nd & nd & nd & nd & nd & nd & $39.93 \pm 0.4$ & nd \\
\hline 3. & Protocatechuic acid & nd & nd & $5.06 \pm 0.03$ & $3.87 \pm 0.01$ & $2.58 \pm 0.01$ & $0.45 \pm 0.01$ & $4.10 \pm 0.32$ & nd & nd & $2.01 \pm 0.2$ \\
\hline 4. & Gentisic acid & nd & nd & nd & nd & nd & nd & nd & nd & nd & nd \\
\hline 5. & Chlorogenic acid & $4.70 \pm 0.01$ & nd & $2.74 \pm 0.02$ & $1.27 \pm 0.2$ & nd & nd & nd & nd & nd & nd \\
\hline 6. & para-OH benzoic acid & $10.16 \pm 0.1$ & nd & $10.81 \pm 0.02$ & nd & $1.25 \pm 0.02$ & nd & $1.02 \pm 0.11$ & nd & nd & nd \\
\hline 7. & Cafeic Acid & $13.61 \pm 0.04$ & nd & $13.98 \pm 0.01$ & $15.86 \pm 0.03$ & nd & $5.34 \pm 0.03$ & $6.39 \pm 0.23$ & $6.81 \pm 0.004$ & nd & nd \\
\hline 8. & Syringic acid & nd & nd & $1.11 \pm 0.04$ & $12.13 \pm 0.01$ & nd & nd & nd & $1.32 \pm 0.02$ & nd & nd \\
\hline 9. & Salicilyc acid & $6.70 \pm 0.03$ & nd & $2.70 \pm 0.03$ & nd & $8.4 \pm 0.01$ & $2.3 \pm 0.05$ & $1.80 \pm 0.01$ & nd & nd & nd \\
\hline 10. & para-coumaric acid & nd & nd & $1.82 \pm 0.001$ & nd & nd & nd & nd & nd & nd & nd \\
\hline 11. & Ferulic acid & $7.58 \pm 0.001$ & nd & $8.99 \pm 0.02$ & $8.06 \pm 0.02$ & $11.52 \pm 0.1$ & $6.14 \pm 0.11$ & $7.81 \pm 0.01$ & $6.88 \pm 0.01$ & $9.93 \pm 0.01$ & nd \\
\hline 12. & Sinapic acid & $5.41 \pm 0.3$ & nd & $12.35 \pm 0.01$ & $4.82 \pm 0.04$ & $7.17 \pm 0.3$ & nd & $2.11 \pm 0.02$ & $1.13 \pm 0.01$ & $19.32 \pm 0.01$ & nd \\
\hline 13. & Trans-cinnamic acid & $5.41 \pm 0.04$ & $1.23 \pm 0.03$ & nd & $3.07 \pm 0.05$ & nd & nd & nd & nd & nd & nd \\
\hline \multicolumn{12}{|c|}{ Flavonoids } \\
\hline 14. & Naringenin & nd & nd & nd & nd & nd & nd & nd & nd & nd & nd \\
\hline 15. & Quercetin & $0.93 \pm 0.01$ & nd & $6.05 \pm 0.02$ & nd & $3.25 \pm 0.01$ & nd & $0.36 \pm 0.02$ & nd & $7.90 \pm 0.01$ & nd \\
\hline 16. & Kampherol & $2.74 \pm 0.01$ & $3.32 \pm 0.001$ & $7.30 \pm 0.01$ & $3.66 \pm 0.01$ & nd & nd & nd & nd & $7.58 \pm 0.01$ & $6.38 \pm 0.01$ \\
\hline \multicolumn{12}{|c|}{ Polyphenol } \\
\hline 17. & Rosmarinic acid & $1.94 \pm 0.002$ & 1.81 & nd & $1.27 \pm 0.01$ & $0.8 \pm 0.2$ & $2.0 \pm 0.001$ & $1.12 \pm 0.01$ & $1.08 \pm 0.02$ & nd & nd \\
\hline & Total phenolic acids & 53.57 & 1.23 & 59.56 & 49.08 & 30.92 & 14.23 & 23.23 & 16.14 & 69.18 & 2.01 \\
\hline leaves & $\begin{array}{c}\text { Ratio } \\
\text { s/stems of phenolic acid }\end{array}$ & \multicolumn{2}{|c|}{$43.51: 1$} & \multicolumn{2}{|c|}{$1.2: 1$} & \multicolumn{2}{|c|}{$2.2: 1$} & \multicolumn{2}{|c|}{$1.4: 1$} & \multicolumn{2}{|c|}{$34.4: 1$} \\
\hline & $\begin{array}{l}\text { Total phenolic acid } \\
\text { (leaves }+ \text { stem })\end{array}$ & \multicolumn{2}{|c|}{54.80} & \multicolumn{2}{|c|}{108.64} & \multicolumn{2}{|c|}{45.15} & \multicolumn{2}{|c|}{39.37} & \multicolumn{2}{|c|}{71.19} \\
\hline & $\begin{array}{l}\text { Total flavonoids } \\
\text { (leaves + stem) }\end{array}$ & \multicolumn{2}{|c|}{6.99} & \multicolumn{2}{|c|}{17.01} & \multicolumn{2}{|c|}{3.25} & \multicolumn{2}{|c|}{0.36} & \multicolumn{2}{|c|}{21.86} \\
\hline
\end{tabular}

${ }^{*}$ mean \pm standard deviation $(\mathrm{n}=3)$ 
$\mu \mathrm{g} / \mathrm{g}$ dry matter), followed by VAR $(71.19 \mu \mathrm{g} / \mathrm{g}$ dry matter), VAA $(54.80 \mu \mathrm{g} / \mathrm{g}$ dry matter $)$, VAP $(45.15 \mu \mathrm{g} / \mathrm{g}$ dry matter) and VAM (39.37 $\mu \mathrm{g} / \mathrm{g}$ dry matter).

The total polyphenols from leaves and stems of $V$. album decreased in the following order: $\mathrm{VAR}>\mathrm{VAF}>\mathrm{VAA}$ $>$ VAP $>$ VAM.

Luczkiewicz et al. (2001), analyzed the phenolic acids present in mistletoe plants hosted by six different hosts. They found that in mistletoe hosted by Malus domestica, the main compound was rosmarinic acid (17.48 $\mathrm{mg} \%$ ), while in mistletoe hosted by Populus nigra, the dominant component was chlorogenic acid (12.34 $\mathrm{mg} \%)$.

Condrat et al. (2009) investigated also nine phanerogam plants (including the european mistletoe) for their flavonoid content and antioxidant activity. Quercetin and kaempferol concentrations were found to be very low in mistletoe extracts $(0.20 \mu \mathrm{mol} / \mathrm{g}$ dry matter, and 0.16 $\mu \mathrm{mol} / \mathrm{g}$ dry matter, respectively).

Our study revealed that the flavanone naringenin was not present in all the varieties of Viscum album investigated. This result is in agreement with the study of Haas et al. (2003) that did not find naringenin in all subspecies of $V$. album analysed, but they found it, rarely, in epicuticular waxes, in V.cruciatum. They also found flavonols (quercetin and occasionally kaempherol, along with some of their methyl derivatives) in epicuticular material of $V$. album.

\section{Antioxidant activity}

Antioxidant properties of aqueous and ethanol extracts from leaves and stems of mistletoe were determined by three methods: their ability to deactivate stable DPPH radical, to inhibit peroxyl radical and deactivation of cation radicals $\mathrm{ABTS}^{*+}$.

A

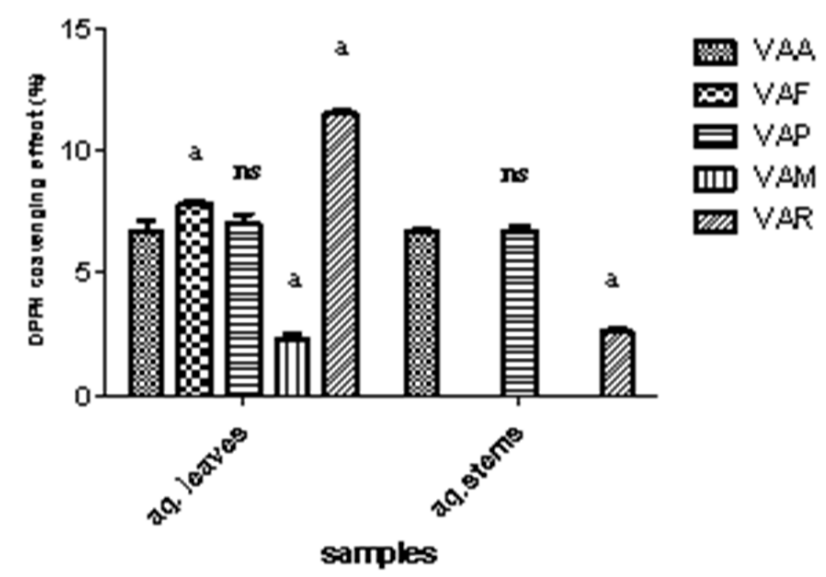

DPPH inhibition by mistletoe extracts

The comparative antioxidant activity of $V$.album leaves hosted by different host trees, evaluated by the DPPH method is presented in Fig. 2. Beetwen all the samples examined, we observed significantly differences $(\mathrm{p}<0.001)$ regarding to DPPH scavenging effect (\%) of aqueous and ethanol extracts in leaves and stems, except the aqueous mistletoe samples from leaves and stems of VAP.

The results showed that DPPH scavenging effect of aqueous extracts from mistletoe leaves varied between $11.49 \%$, in the case of mistletoe growing on Robinia pseudoacacia (VAR), to $2.22 \%$ in the case of VAM (mistletoe growing on Malus domestica). Higher DPPH scavenging effect was observed in the ethanol extracts, with values ranging from $77.19 \%$ (VAF) to $50.47 \%$ (VAA).

The DPPH scavenging effect of extracts of mistletoe stems was lower than that of leaf extracts. No antioxidant activity was detected in aqueous extracts of VAF and VAM stems.

In all samples, stem extracts have lower antioxidant activity than the corresponding leaf extracts, also in the case of ethanol extracts.

Similar results were obtained by ÖnayUçar et al. (2006), who investigated the antioxidant activity of methanol extracts of V.album grown on different host trees. Their results showed that mistletoe hosted by Robinia pseudocacia (VAR) exhibited $73.44 \%$ inhibition of DPPH, and mistletoe hosted by Acer campestre (VAA) presented $59.52 \%$ inhibition of DPPH. The slight differences between our results and theirs can be assigned to the solvent used for extraction and/or to environmental factors.

Sharma and Bhat (2010), showed that the absorbance profiles of DPPH were highest in a buffered methanol solution, followed by methanol and ethanol solutions.

Fig. 2. DPPH scavenging effect (\%) of aqueous (aq.) (A) versus ethanol (et.) (B) extracts of mistletoe leaves and stems harvested in July 2009, from five different host trees. The data were expresed as means \pm standard deviation $(n=3)$ and evaluated by one-way ANOVA to compare each extract to VAA extract. Differences were considered to be statistically significant if $\mathrm{p}<0.05$; ns- no significant differences; a- $\mathrm{p}<0.001$ 
54

Higher absorbance in methanol solutions implies better sensitivity vis-à-vis ethanol solutions of DPPH.

Roman et al. (2009) investigated the efficiency of ultrafiltration process on the antioxidant activity of aqueous extract of $V$. album. The values obtained by the DPPH assay ranged between $66.2 \%$ and $88.2 \%$ DPPH inhibition for mistletoe concentrated extracts. The correlation coefficient between data of DPPH inhibition and total protein content was 0.94 , suggesting that, besides the phenolic compounds of Viscum extracts, viscolectins have a great contribution to the radical scavenging activity.

Other research paper (Oluwaseun and Ganiyu, 2008) investigated the antioxidant properties of methanol extracts of $V$. album isolated from cocoa and cashew trees in the South Western part of Nigeria. The scavenging ability of each methanol extract against DPPH followed a dose-dependent pattern $(0-10 \mathrm{mg} / \mathrm{ml})$. The free radical scavenging ability of the $V$. album extract from cocoa tree performs better than that from cashew tree, a fact that is in agreement with the total phenol content of the two extracts $(182 \mathrm{mg} / 100 \mathrm{~g}$, and $160 \mathrm{mg} / 100 \mathrm{~g}$, respectively).

When the activities of the same type of mistletoe extracts, collected from the same host tree, but in different seasons, were compared using the DPPH assay, it was found that the antioxidant activity was, in general, higher in spring (Vicaş et al., 2008). The values obtained in May 2008 by the DPPH assay varied from $42.2 \% \mathrm{DPPH}$ inhibition for V.album growing on Robinia pseudocacia (VAR) to $17.4 \%$ DPPH inhibition for V. album growing on Populus nigra (VAP). In July, the VAR extracts exhibited the highest capacity to scavenge free radicals (46.91\%), but the VAA and VAP extracts lost their antioxidant activity. The differences may be explained by the different environmental factors (temperature, water, irradiation, etc.)

\section{ORAC method}

The values obtained by ORAC assays are shown in Tab. 2 , and varied from $10.73 \pm 1.90 \mathrm{mM}$ Trolox equivalents $/ \mathrm{g}$ fresh matter for the VAP ethanol leaf extract, to $1.52 \pm$ $1.25 \mathrm{mM}$ Trolox equivalents/g fresh matter for the VAM aqueous stem extract. According to the results obtained in the ORAC assay, there was no significant differences between the antioxidant capacity of leaves and stems for all variants of mistletoe investigated, except for the aqueous leaf extracts of VAA vs VAM ( $\mathrm{p}<0.01)$, and for the aqueous stem extracts of VAA $v$ VAM $(\mathrm{p}<0.05)$.

The highest values were recorded in the case of VAA aqueous leaf extract $(5.49 \mathrm{mM}$ Trolox equivalents/g fresh matter) and VAP ethanol leaf extract $(10.73 \mathrm{mM}$ Trolox equivalents/g fresh matter).

Our results showed that the ethanol extracts exhibit the highest ability to inhibit peroxyl radicals. These results are in concordance with data obtained by Al-Duais et al. (2009), who reported $103.3 \pm 2.5 \mathrm{mmol} / 100 \mathrm{~g}$ Trolox equivalents in ethanol leaf extracts of Cyphostemma digitatum (Vitaceae), as compared to $16.7 \mathrm{mmol} / 100 \mathrm{~g}$ Trolox equivalents in water extracts.
Tab. 2. Antioxidant capacity (as determined by the ORAC assay) of fresh leaves and stems from mistletoe (in water and ethanol extracts)

\begin{tabular}{|c|c|c|}
\hline \multirow[t]{2}{*}{ Mistletoe samples } & \multicolumn{2}{|c|}{$\begin{array}{c}\text { ORAC } \\
\text { (mM equivalents Trolox/ } \\
\text { g fresh matter) }{ }^{*}\end{array}$} \\
\hline & Aqueous extract & Ethanol extract \\
\hline \multicolumn{3}{|l|}{ Leaves } \\
\hline VAA (Acer campestre) & $6.33 \pm 1.42$ & $9.42 \pm 0.25$ \\
\hline VAF (Fraxinus excelsior) & $3.55 \pm 2.65^{\mathrm{ns}}$ & $10.04 \pm 0.40^{\mathrm{ns}}$ \\
\hline VAP (Populus nigra) & $3.96 \pm 0.31^{\text {ns }}$ & $10.73 \pm 1.90^{\mathrm{ns}}$ \\
\hline VAM (Malus domestica) & $1.87 \pm 1.25^{*}$ & $9.30 \pm 0.55^{\mathrm{ns}}$ \\
\hline VAR (Robinia pseudoacacia) & $3.43 \pm 1.57^{\mathrm{ns}}$ & $9.97 \pm 1.84^{\mathrm{ns}}$ \\
\hline \multicolumn{3}{|l|}{ Stems } \\
\hline VAA (Acer campestre) & $5.49 \pm 2.73$ & $9.37 \pm 0.14$ \\
\hline VAF (Fraxinus excelsior) & $2.42 \pm 3.68^{\mathrm{ns}}$ & $9.88 \pm 1.24^{\mathrm{ns}}$ \\
\hline VAP (Populus nigra) & $2.07 \pm 0.27^{\mathrm{ns}}$ & $9.19 \pm 1.78^{\mathrm{ns}}$ \\
\hline VAM (Malus domestica) & $1.52 \pm 1.25^{\circ}$ & $9.29 \pm 1.40^{\mathrm{ns}}$ \\
\hline VAR (Robinia pseudoacacia) & $3.25 \pm 2.19^{\mathrm{ns}}$ & $9.79 \pm 0.87^{\mathrm{ns}}$ \\
\hline
\end{tabular}

${ }^{*}$ The data were expresed as means \pm standard deviation $(n=3)$ and evaluated by one-way ANOVA to compare each extract to VAA extract. Differences were considered to be statistically significant if $\mathrm{p}<0.05$. ns-no significant differences; ${ }^{*} \mathrm{p}<0.05 ;{ }^{* *} \mathrm{p}<0.01$

\section{TEAC assay}

Based upon the conducted research, it has been found that all mistletoe extracts (aqueous or ethanol, leaf or stem) have the ability of scavenging cation-radicals $\mathrm{ABTS}^{*+}$ ( Tab. 3). According to the results obtained with TEAC assays, there were significant differences $(\mathrm{p}<0.001)$ between all the extracts investigated.

The highest level of scavenging radicals was detected in water extracts, and ethanol extracts had the lowest deactivation level. Aqueous leaf and stem extracts of mistletoe growing on Acer campestre (VAA) recorded the highest TEAC values $(678.72 \pm 0.00 \mathrm{mM}$ equivalent Trolox/g fresh matter, and $577.94 \pm 0.01 \mathrm{mM}$ equivalent Trolox/g fresh matter, respectively), while for the ethanol extracts the highest level of scavenging cation-radicals $\mathrm{ABTS}^{++}$ was recorded for leaves from VAF $(461.09 \pm 0.11 \mathrm{mM}$ equivalent Trolox/g fresh matter) and for stems from VAP (306.68 $\pm 0.01 \mathrm{mM}$ equivalent Trolox/g fresh matter). We may suppose that water extracts had the higest antioxidant activity because they contain more bioactive compounds with the ability of scavenging cation-radicals $\mathrm{ABTS}^{+}$, as compared to ethanol extracts.

When aqueous extracts of green tea were compared with methanol extracts, Drużyńska et al. (2007) found that the former had the highest level of activity for scavenging cation-radicals $\mathrm{ABTS}^{*+}$, because catechins are hydrosoluble. The authors supposed that catechins conferred the ability to scavenge cation-radicals to the green tea extracts.

\section{Folin Ciocalteu method}

Total phenolic content, determined by reaction with the Folin-Ciocalteu reagent, was expressed as mg gallic 
acid equivalent $/ \mathrm{g}$ fresh matter (GAE/FW). The results are shown in Tab. 4. Significant differences $(\mathrm{p}<0.001)$ in the total phenolic content of aqueous and ethanolic extracts were observed. In aqueous leaf extracts, the highest polyphenolic content was found in VAR $(200.51 \pm 0.00 \mathrm{mg}$ GAE/g fresh matter, while the lowest value was $176.87 \pm$ $0.003 \mathrm{mg} \mathrm{GAE} / \mathrm{g}$ fresh matter for VAM. The values obtained for total phenolics in both, aqueous and ethanol extracts, decreased in the order: VAR > VAF > VAP > VAA $>$ VAM. The mistletoe stem extracts contained lower levels of phenolics than the leaf extracts, in both solvents. The lowest level of total phenolics was recorded for VAF and VAA aqueous stem extracts (58\% and 54,97\% less that leaves, respectively). In the other extracts (VAM or VAR), the differences between leaves and stems were not significant.

Tab. 3. Antioxidant potential (as determined by the TEAC assay) of fresh leaves and stems from mistletoe (in water and ethanol extracts)

\begin{tabular}{|c|c|c|}
\hline \multirow[t]{2}{*}{ Mistletoe Samples } & \multicolumn{2}{|c|}{$\begin{array}{c}\text { TEAC } \\
\text { (mM equivalents Trolox } / \mathrm{g} \text { fresh matter) }\end{array}$} \\
\hline & Aqueous extract & Ethanol extract \\
\hline \multicolumn{3}{|l|}{ Leaves } \\
\hline VAA (Acer campestre) & $678.72 \pm 0.00$ & $312.18 \pm 0.00$ \\
\hline VAF (Fraxinus excelsior) & $496.32 \pm 0.01 \cdots$ & $461.09 \pm 0.11 \cdots$ \\
\hline VAP (Populus nigra) & $401.81 \pm 0.01^{\cdots}$ & $365.78 \pm 0.01^{\cdots}$ \\
\hline VAM (Malus domestica) & $473.09 \pm 0.01^{\cdots}$ & $215.28 \pm 0.01^{* *}$ \\
\hline VAR (Robinia pseudoacacia) & $592.05 \pm 0.01^{\cdots \cdots}$ & $417.78 \pm 0.03 \cdots$ \\
\hline \multicolumn{3}{|l|}{ Stem } \\
\hline VAA (Acer campestre) & $577.94 \pm 0.01$ & $281.60 \pm 0.02$ \\
\hline VAF (Fraxinus excelsior) & $333.77 \pm 0.00 \cdots$ & $258.00 \pm 0.00$ \\
\hline VAP (Populus nigra) & $363.95 \pm 0.01^{\cdots}$ & $306.68 \pm 0.01 \cdots$ \\
\hline VAM (Malus domestica) & $325.04 \pm 0.00$ & $213.92 \pm 0.02 \cdots$ \\
\hline VAR (Robinia pseudoacacia) & $541.84 \pm 0.01^{\cdots \cdots}$ & $209.59 \pm 0.01^{\cdots}$ \\
\hline
\end{tabular}

${ }^{*}$ The data were expresed as means \pm standard deviation $(n=3)$ and evaluated by one-way ANOVA to compare each extract to VAA extract.. Differences were considered to be statistically significant if $\mathrm{p}<0.05 .{ }^{* * *} \mathrm{p}<0.001$

Tab. 4. Total phenolic content of $V$. album leaves and stems (aqueous and ethanol extracts)

\begin{tabular}{ccc}
\hline \multirow{2}{*}{ Samples } & \multicolumn{2}{c}{ mg GAE/g fresh matter } \\
\cline { 2 - 3 } & Aqueous extract & Ethanol extract \\
\hline Leaves & \\
\hline VAA (Acer campestre) & $192.65 \pm 0.002$ & $32.16 \pm 0.003$ \\
VAF (Fraxinus excelsior) & $199.88 \pm 0.002 \cdots$ & $46.85 \pm 0.005^{\cdots}$ \\
VAP (Populus nigra) & $195.03 \pm 0.007 \cdots$ & $45.03 \pm 0.02 \cdots$ \\
VAM (Malus domestica) & $176.87 \pm 0.003^{\cdots}$ & $31.32 \pm 0.008^{\cdots}$ \\
VAR (Robinia pseudoacacia) & $200.51 \pm 0.00 \cdots$ & $65.30 \pm 0.002 \cdots$ \\
\hline Stem & \\
\hline VAA (Acer campestre) & $166.94 \pm 0.003$ & $23.86 \pm 0.013$ \\
VAF (Fraxinus excelsior) & $152.11 \pm 0.001 \cdots$ & $36.22 \pm 0.014 \cdots$ \\
VAP (Populus nigra) & $189.77 \pm 0.005^{\cdots}$ & $42.45 \pm 0.008^{\cdots}$ \\
VAM (Malus domestica) & $161.41 \pm 0.005$ & $30.22 \pm 0.001^{\cdots}$ \\
VAR (Robinia pseudoacacia) & $186.93 \pm 0.003$ & $27.96 \pm 0.002 \cdots$ \\
\hline
\end{tabular}

** The data were expresed as means \pm standard deviation $(\mathrm{n}=3)$ and evaluated by one-way ANOVA to compare each extract to VAA extract.. Differences were considered to be statistically significant if $\mathrm{p}<0.05 .{ }^{* * *} \mathrm{p}<0.001$
In a recent research paper (Vicaş et al., 2009), it was shown that methanolic extracts of $V$. album, harvested in December 2008, were rich in phenolics, potential antioxidants, with ferric reducing ability. In that case, mistletoe leaves originating from Acer campestre (VAA), showed the highest concentration of phenolics, followed by VAM and VAF. These results can be explained by the influence of harvesting time on the chemical composition and antioxidant activity.

The data presented in Tab. 5 show that the highest antioxidant index score was recorded from ethanol extracts, particulary for leaves VAF ( $97.85 \%)$, followed by $\operatorname{VAR}(88.77 \%)$. For the aqueous extracts, the highest antioxidant index score was registered for VAA (85.93\%), followed by VAR (80.47\%). Both, leaf and stem extracts exhibited antioxidant activity, but generally it was higher for leaves.

The antioxidant potential determined by the ORAC and TEAC methods (Tab. 5) were combined into a single, mean antioxidant index score and correlated with the plenolics concentration, determined by the Folin-Ciocalteu method, as presented in Fig. 3. We found a weak correlation beetwen this index and the phenolics' content, nonsignificant for the aqueous extract $\left(R^{2}=0.167\right)$ or the ethanolic extract $\left(R^{2}=0.62\right)$.

\section{Conclusions}

The influence of the host tree may have a key role in the phenolic composition of mistletoe leaves or stems. In this study, mistletoe hosted by Fraxinus excelsior (VAF) proved to be the richest in phenolic acids $(108.64 \mu \mathrm{g} / \mathrm{g}$ dry matter), followed by VAR (71.19 $\mu \mathrm{g} / \mathrm{g}$ dry matter), VAA $(54.79 \mu \mathrm{g} / \mathrm{g}$ dry matter $), \mathrm{VAP}(45.15 \mu \mathrm{g} / \mathrm{g}$ dry matter $)$ and VAM $(39.37 \mu \mathrm{g} / \mathrm{g}$ dry matter), as determined by HPLC. The total polyphenols from leaves and stems of $V$. album decreased in the following order: VAR $>$ VAF $>$ VAA $>$ VAP $>$ VAM. In aqueous leaf extracts, the highest polyphenolic content was found in VAR $(200.51 \pm 0.00 \mathrm{mg}$ $\mathrm{GAE} / \mathrm{g}$ fresh matter, while the lowest value was 176.87 $\pm 0.003 \mathrm{mg} \mathrm{GAE} / \mathrm{g}$ fresh matter for VAM. The values obtained for total phenolics in both, aqueous and ethanol extracts, decreased in the order: VAR > VAF > VAP > VAA $>$ VAM. The mistletoe stem extracts contained lower levels of phenolics, as compared to leaves, in both solvents. Our research paper, showed that the bioactive compounds and the antioxidant activity are present in leaves and also in stems, in all the misteltoe samples examinated (aqueous and ethanol). Of the samples examined, the best results were obtained with ethanolic extract of VAF, followed by VAR. As it has been observed by other authors (Cao and Prior, 1998), the values obtained for the antioxidant capacity of an extract depend greatly on the methodology used. In our measurements, no correlations were established between the antioxidant score determined by DPPH, ORAC and TEAC methods. In the case of hydrosoluble extracts, DPPH measurements, based on free radi- 
Tab. 5. Individual Antioxidant index scores *and Mean antioxidant index scores* calculated index in leaves and stems of mistletoe (aqueous and ethanol extracts). The values are compared with total phenolics***, as determined by the Folin-Ciocalteu method (last columns)

\begin{tabular}{|c|c|c|c|c|c|c|c|c|c|c|}
\hline \multirow{3}{*}{ Sample } & \multicolumn{10}{|c|}{ Antioxidant index score ${ }^{*}$} \\
\hline & \multicolumn{2}{|c|}{ DPPH } & \multicolumn{2}{|c|}{ ORAC } & \multicolumn{2}{|c|}{ TEAC } & \multicolumn{2}{|c|}{ Mean score ${ }^{* *}$} & \multicolumn{2}{|c|}{ Total phenolics*** } \\
\hline & $\begin{array}{c}\text { Aqueous } \\
\text { extract }\end{array}$ & $\begin{array}{c}\text { Ethanol } \\
\text { extract }\end{array}$ & $\begin{array}{c}\text { Aqueous } \\
\text { extract }\end{array}$ & $\begin{array}{c}\text { Ethanol } \\
\text { extract }\end{array}$ & $\begin{array}{c}\text { Aqueous } \\
\text { extract }\end{array}$ & $\begin{array}{c}\text { Ethanol } \\
\text { extract }\end{array}$ & $\begin{array}{c}\text { Aqueous } \\
\text { extract }\end{array}$ & $\begin{array}{c}\text { Ethanol } \\
\text { extract }\end{array}$ & $\begin{array}{c}\text { Aqueous } \\
\text { extract }\end{array}$ & $\begin{array}{l}\text { Ethanol } \\
\text { extract }\end{array}$ \\
\hline \multicolumn{11}{|c|}{ Leaves } \\
\hline VAA & 57.79 & 65.38 & 100.00 & 87.79 & 100.00 & 67.70 & 85.93 & 73.63 & 96.08 & 49.25 \\
\hline VAF & 68.15 & 100.00 & 56.12 & 93.55 & 73.13 & 100.00 & 65.80 & 97.85 & 99.68 & 71.74 \\
\hline VAP & 60.75 & 71.33 & 62.55 & 100.00 & 59.20 & 79.33 & 60.83 & 83.55 & 97.27 & 68.69 \\
\hline VAM & 19.32 & 76.51 & 29.53 & 86.66 & 69.70 & 46.69 & 39.52 & 69.95 & 88.21 & 47.96 \\
\hline VAR & 100.00 & 82.80 & 54.19 & 92.92 & 87.23 & 90.61 & 80.47 & 88.77 & 100.00 & 100.00 \\
\hline \multicolumn{11}{|c|}{ Stem } \\
\hline VAA & 57.79 & 54.46 & 86.73 & 87.33 & 85.15 & 61.07 & 76.56 & 67.62 & 83.26 & 36.54 \\
\hline VAF & 0.00 & 48.18 & 38.21 & 92.08 & 49.18 & 55.95 & 29.13 & 65.40 & 75.86 & 55.47 \\
\hline VAP & 58.49 & 52.70 & 32.67 & 85.66 & 53.62 & 66.51 & 48.26 & 68.29 & 94.64 & 65.01 \\
\hline VAM & 0.00 & 69.45 & 23.96 & 86.59 & 47.89 & 46.39 & 23.95 & 67.48 & 80.50 & 46.28 \\
\hline VAR & 22.28 & 79.93 & 51.34 & 91.28 & 79.83 & 45.46 & 51.15 & 72.22 & 93.23 & 42.82 \\
\hline
\end{tabular}

${ }^{*}$ antioxidant index score $=[($ sample score/best score $) \mathrm{x} 100] ;{ }^{* *}$ mean antioxidant index score by cumulating the DPPH, ORAC and TEAC scores

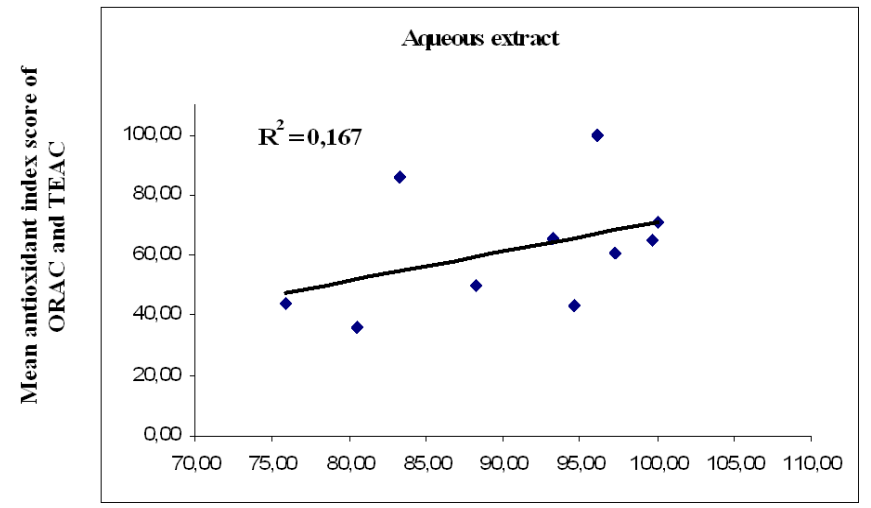

Total phenols ( mg GAE/ g fresh mattaer)

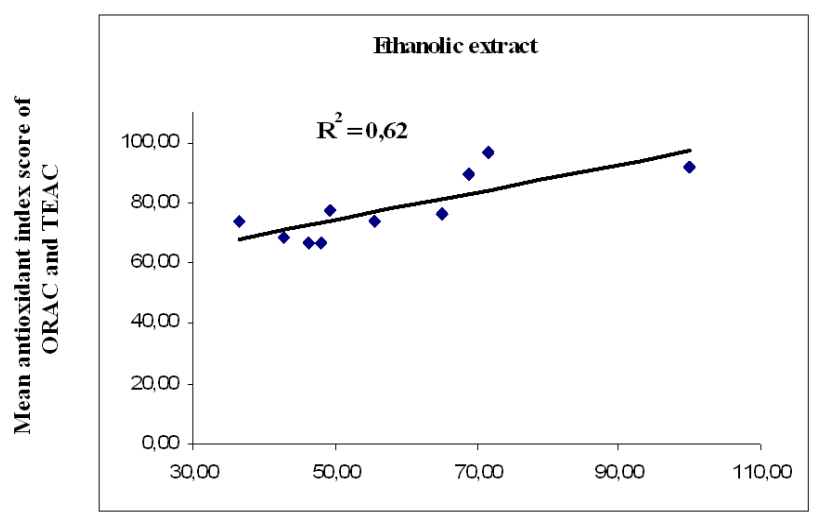

Total phenols ( mg GAE/ g fresh mattaer)

Fig. 3. Correlation between mean antioxidant index scores (determined in aqueous and ethanolic extracts), obtained by combination of the two antioxidant methods used (ORAC and TEAC), and total concentration of phenolics (mg GAE/g fresh matter) determined by the Folin-Ciocalteu method

cal scavenging, seem to be non-relevant, while the methods based on cation redox changes are more relevant for ethanol or aqueous extracts. So, we combined into a single, mean antioxidant index, the score obtained by the ORAC and TEAC methods. No significant correlations with the plenolics concentration were obtained, suggesting that the antioxidant potential is reflected by a more complex synergy of active molecules, not only phenolics. The differences in antioxidant activity between leaves and stems of mistletoes harvested from different trees can be attributed to environmental factors such as season, climate and temperature which can significantly affect the accumulation of the antioxidant components in the plant tissue.

\section{Acknowledgements}

This work was supported by CNCSIS-UEFISCSU, project number 1120, PN II-IDEI 696/2008, Romania.

\section{References}

Al-Duais M, Müller L, Böhm V, Jetschke G (2009). Antioxidant capacity and total phenolics of Cyphostemma digitatum before and after processing: use different assays. Eur Food Res Technol 228:813-821.

Antal DS (2010). Medicinal plants with antioxidant properties from Banat region (Romania): A rich pool for the discovery of multi-target phytochemicals active in free-radical related disorders. Analele Universitatii din Oradea-Fascicula Biologie Tom. XVII/1:14-22.

Aqil F, Ahmad I, Mehmood Z (2006). Antioxidant and free radical scavenging properties of twelve traditionally used Indian medicinal plants. Turk J Biol 30:177-183.

Arnao MB, Cano A, Alcolea JF, Acosta M (2001). Estimation of free radical quenching activity of leaf pigment extracts. Phytochem Anal 12:138-143. 
Borneo R, León AE, Aguirre A, Ribotta P, Cantero JJ (2009). Antioxidant capacity of medicinal plants from the Province of Córdoba (Argentina) and their in vitro testing in a model food system. Food Chemistry 112 (3):664-670.

Brand-Williams W, Cuvelier ME, Berset C (1995). Use of a free radical method to evaluate antioxidant activity. Lebensmittel-Wissenschaft und Technologie/Food Science and Technology 28:25-30.

Cao G, Prior RL (1998). Comparison of different analytical methods for assessing total antioxidant capacity of human serum. Clin Chem 44:1309-1315.

Choudhary MI, Maher S, Begum A, Abbaskhan A, Ali S, Khan A, Rehman S, Rahman A (2010). Characterization and Antiglycation Activity of Phenolic Constituents from Viscum album (European Mistletoe). Chem Pharm Bull 58 (7):980-982.

Condrat D, Szabo MR, Crisan F, Lupea A-X (2009). Antioxidant activity of some phanerogam plant extracts. Food Science and Technology Research 15(1):95-98.

Djeridane A, Yousfi M, Brunel JM, Stocker P (2010). Isolation and characterization of a new steroid derivative as a powerful antioxidant from Cleome Arabica in screening the in vitro antioxidant capacity of 18 Algerian medicinal plants. Food Chem Toxicol 48(10):2599-2606.

Drużyńska B, Stępniewska A, Wołosiak R (2007). The influence of time and type of solvent on efficiency of the extraction of polyphenols from green tea and antioxidant properties obtained extracts. Acta Sci Pol Technol Aliment 6(1):2736.

Edlund U, Henzel A, Frose D, Pfuller U, Scheffler A (2000). Polysaccharides from fresh Viscum album L berry extract and their interaction with Viscum album agglutin I. Arzneimittelforschung 50:645-651.

Graf E (1992). Antioxidant potential of ferulic acid. Free Radic Bio Med 13(4):435-448.

Haas K, Bauer M, Wollenweber E (2003). Cuticular waxes and flavonol aglycones of mistletoes. Z Naturforsch 58c:464470.

Hajtó T, Hostanska K, Berki T, Pálinkás L, Boldizsár F, Németh P (2005). Oncopharmacological perspectives of a plant lectin (Viscum album Agglutinin-I): overview of recent results from in vitro experiments and in vivo animal models, and their possible relevance for clinical applications. Evid Based Complement Alternat Med 2:59-67.

Huang D, Ou B, Hampsch-Woodill M, Flanagan JA, Prior RL (2002). High-throughput assay of oxygen radical absorbance capacity (ORAC) using a multichannel liquid handling system coupled with a microplate fluorescence reader in 96well format. J Agric Food Chem 50(16):4437-44.

Kratchanova M, Denev P, Ciz M, Lojek A, Mihailov A (2010). Evaluation of antioxidant activity of medicinal plants containing polyphenol compounds. Comparison of two extraction systems. Acta Bioch Polonica 57(2):229-234.

Leu Y-L, Hwang T-L, Chung Y-M, Hong P-Y (2006). The inhibition of superoxide anion generation in human neutrophils by Viscum coloratum. Chem Pharm Bull 54:1063-1066.
Li H-B, Wong C-C, Cheng K-W, Chen F (2008). Antioxidant properties in vitro and total phenolic contents in methanol extracts from medicinal plants. Food Sci Tech 41(3):385390.

Luczkiewicz M, Cisowski W, Kaiser P, Ochocka R, Piotrowski A (2001). Comparative analysis of phenolic acids in mistletoe plants from various hosts. Acta Poloniae PharmaceuticaDrug Research 58(5):373-379.

Markham KR (1982). Techniques of Flavonoid Identification. Academic Press, p. 15-16.

Materska M (2008). Quercetin and its derivatives-a review. Pol J Food Nutr Sci 58(4):407-413.

Miliauskas G, Venskutonis PR, VanBeek TA (2004). Screening of radical scavenging activity of some medicinal and aromatic plant extracts. Food Chem 85:231-237.

Oluwaseun AA, Ganiyu O (2008). Antioxidant properties of methanolic extracts of mistletoes (Viscum album) from cocoa and cashew trees in Nigeria. African J Biotech 7(17):3138 3142.

ÖnayUçar E, Karagöz A, Arda N (2006). Antioxidant activity of Viscum album ssp. album. Fitoterapia 77: 556-560.

Peng HY, Zhang YH, Han Y, Wang M (2005). Studies on the anticancer effects of total alkaloid from Viscum coloratum. Zhongguo Yhong Yao Za Zhi 30:381-387.

Romagnoli S, Ugolini R, Fogolari F, Schaller G, Urech K, M Giannattasio, Ragona L, Molinari H (2000). NMR structural determination of viscotoxin A3 from Viscum album L. Biochem J 350:569-577.

Roman GP, Neagu E, Radu GL (2009). Antiradical activities of Salvia officinalis and Viscum album L. Extracts concentrated by ultrafiltration process. Acta Sci Pol Technol Aliment $8(3): 47-58$.

Seeram NP, Aviram M, Zhang Y, Henning SM, Feng L, Dreher M, Heber D (2008). Comparison of antioxidant potency of commonly consumed polyphenol-rich beverages in the United States. J Agric Food Chem 56: 1415-1422.

Sharma OP, Bhat TK (2010). DPPH antioxidant assay revisited. Food Chemistry 113:1202-1205.

Shi Z-M, Feng P, Jiang D-Q, Wang X-J (2006). Mistletoe alkali inhibits peroxidation in rat liver and kidney. World J Castroenterol 12:4052-4055.

Singleton VL, Orthofer R, Lamuela-Raventos RM (1999). Analysis of total phenols and other oxidation substrates and antioxidants by means of Folin-Ciocalteu reagent. Meth Enzymol 299:152-178.

Vicaş S, Rugina D, Socaciu C (2008). Antioxidant activities of Viscum album's leaves from various host trees. Bulletin UASVM. Agriculture Cluj-Napoca 65(1):327-332.

Vicaş S, Prokisch J, Rugina D, Socaciu C (2009). Hydrophilic and Lipophilic Antioxidant Activities of Mistletoe (Viscum album) as determined by FRAP method. Not Bot Hort Agrobot Cluj 37(2):112-116.

Yao H, Liao Z-X, Wu Q, Lei G-Q, Liu Z-J, Chen D-F, Chen J-K, Zhou T-S (2006). Antioxidative flavanone glycosides from the branches and leaves of Viscum coloratum. Chem Pharm Bull 54:133-135. 